\title{
Risk reduction in musculoskeletal practice assistance professional nursing pilot in semi intensive care unit
}

\author{
Lemo A, Silva A G, Tucherman M, Talerman C, Guastelli R L e Borba C L \\ Centre for Occupational Health, Albert Einstein Hospital Israeli Brazilian Benefit Society, Address: Avenue \\ Albert Einstein, 627, São Paulo, SP, Brazil
}

\begin{abstract}
The hospitals mostly have a high level of complexity, diversity of services and, consequently, occupational risks. The tasks of mobilization and manual repositioning of patients may require professional of the physical demands due to the weight or excessive patient dependency, attitudes arising from inadequate to lean on a bed or work in a restricted area, sudden weight change that can occur if a patient loses balance or strength to change the position or while moving. These, among many other factors can cause or aggravate musculoskeletal problems in health care workers. These diseases translate into frequent musculoskeletal complaints, high rates of absenteeism, licenses and problems of prolonged labor, creating a vicious cycle that compromises patient safety and performance of institutions. The literature has suggested the administration of courses on handling and transportation of patients as one of the most important strategies to reduce the incidence of problems in the spine between the worker's healths. An exercise program emphasizing global distension and strength, mainly the posterior chain muscles (dorsal region), held twice a week, combined with an approach to ergonomics can reduce musculoskeletal symptoms and absenteeism in nursing.
\end{abstract}

Keywords: ergonomics, musculoskeletal disorders, nursing, hospital

\section{Introduction}

The hospitals are associated with the provision of health services, in order to care, treatment and healing of those affected by the disease. However, also are responsible for the occurrence of a series of risks to health of those working there. Most hospitals have high level structure of complexity and diversity of services and, consequently, occupational risks. There is an extensive list of damage to all organ systems, including musculoskeletal problems, which are often very hot in the nursing staff.

Researchers and organizations from around the world have highlighted the nursing staff as a risk group in relation to musculoskeletal disorders. Among these disorders, there is the low back pain. Low back pain has been particularly well studied among health workers, and results cumulative trauma. The occupational back injuries occur more often when it is performed direct patient care, especially the lifting of [7].
Low back pain is an occupational disease nursing not officially recognized, since there is no legislation setting the maximum load to be carried by nurses, such as what happens in the industry [1]. Among the various activities performed by the nursing is moving patients in bed, which aims to provide security and comfort to the patient, focusing on the recovery of their health [11].

The World Health Organization (1983), through the report "Occupational Hazards in Hospitals", admits that ergonomic problems characteristic of hospitals seem to be handling and transport of patients.

In Brazil, the hospital is considered an institution integrated into the tertiary sector of the economy, which has three degree of risk due to unsafe operations carried out there and the presence of biological agents responsible for infections caused by viruses, fungi and bacteria. ${ }^{*}$ The hospital also has a number of other risks arising

\footnotetext{
* Corresponding author e-mail a.lemo@ig.com.br
} 
from physical, chemical, psychosocial and ergonomic, which can be harmful to the health of workers and therefore should be analyzed so that they can characterize the working conditions in each institution [10].

The concern with the conditions of nursing work in hospitals attract the attention of many researchers because of the risks that the environment offers and painful aspects of the activities peculiar to nursing care, among which stand out the contempt of biological rhythm and timing food, the lack of working program, traveled long distances during the work shift, scale, and lack of furniture inappropriate, inadequate or inappropriate material.

Nursing is faced with complex situations at work, where there is interaction of various tasks leading to a high workload across physical components (related to the effort expended by the skeletal muscle or physiological cost to the individual regarding the the task), cognitive (related to content and organization of tasks, as well as the rate of brain work) and psychological (related to the level of conflict with in the conscious or unconscious representation of the relationship between the person and the situation work) [12].

The nursing staff, as any professional who provides services, has a certain peculiarity in the development of this work, and this watch different "patients" at different times.

The care is the most important instrument in nursing through him develop activities whose primary purpose is to assist the sick and healthy human being. Each caregiver (nursing workers) in their daily lives, particularizes the form or mode of equipping their actions or activities and each of these features is so individualized and characteristic, though the technique is the same. It is necessary that this representation of activities to be studied or analyzed from a technical stand point and scientific, which also can interpret the activity not only physical but also mental activity, which is an important aspect in driving and how to make [4].

The literature has suggested the administration of courses on handling and transportation of patients as one of the most important strategies to re-duce the incidence of spinal problems among health workers [3]. A program of exercises performed twice a week with an approach to ergonomics can reduce musculoskeletal symptoms in nursing personnel [2]. A randomized into two groups, held with workers from a geriatric hospital showed statistically significant reduction in complaints and intensity of back pain in the group who performed strength training, endurance and coordination [6].

\section{Goals}

Identify the hazards for musculoskeletal disorders and its correlation with care, reduce ergonomic risk through interventions in the work organization of nursing care, reduce the incidence of musculoskeletal disorders through res-job training for mobilization and transfer of patients, and physical activity focused on stretching and strengthening global muscle.

\section{Methodology}

Participated in the study group of experts in nursing, semi-intensive sector $(\mathrm{n}=71)$ of a large hospital. Methods were used to analyze the process and organization of relief work as an interview with the coordination of nursing to identifying the impact ergonomics industry.

We developed a practical training in conjunction with the Department of Continuing Education with Realistic Simulation methodology through technical scenarios that replicate real-life experiences and fosters a collaborative environment and interactivity.

Through management reports of absenteeism and postural evaluation questionnaire were selected from only those nurses who presented with musculoskeletal complaints away from work for 15 days $(n=11)$. These professionals, we applied the visual analogue pain scale (0 to 10$)$, assessment of physical indicators such as flexibility of the lumbar spine (posterior muscular chain) using the test of anterior trunk with arms outstretched, measuring the distance from 3rd finger of the hand to the ground, the test sit and reach, measuring the distance achieved with the arms in a sitting position, and muscle strength of the column back injury using the dynamometer type DS in the pre and post intervention of a program holistic fitness (exercise overall) made 01 once a week, 01 hours daily, the total period of 12 weeks. Statistical analysis was used to test "Student t" through the GraphPad Instat ${ }^{\circledR}$.

\section{Results}

According to the evaluation questionnaire postural activities that disturb these work- 
ers were more related to the transfer of patient's dependent, changing positions in bed and bath or shower, because they require flexion and/ or trunk rotation in large amplitudes. After the program, there was a reduction in the number of days of absenteeism related to musculoskeletal disorders in the nursing team of technicians from 210 to $98(53 \%)$ and particularly in the group who carried out the holistic exercise program from 58 to $33(43 \%)$, reduction in visual analogue scale of pain of $6.18 \pm 2.18$ to $2.81 \pm 2.13(\mathrm{p} \leq 0,0006)$, increased flexibility of the lumbar spine of $9.54 \pm 9,27$ to $5.72 \pm 6.06(p \leq 0,0039)$ standing (decrease of the distance of the $3 \mathrm{rd}$ finger of the hand to the ground) and $63.27 \pm 11.03$ to $72.18 \pm 8.01(\mathrm{p} \leq 0,001$ 1) sitting (sit and reach), and increased muscle strength (grip strength) of the lumbar spine of $56.36 \pm 14.05$ to $67.72 \pm 17.51(\mathrm{p} \leq 0,0003)$.

\section{Discussion}

The work of nursing is not only unhealthy, it is also painful, Brazilian legislation admits unhealthy and dangerous. Thus, we must charge of companies, hospital or not, measures to prevent and control factors that make for workers, much easier and less strenuous, stressful, uncomfortable or distressing, performing their daily tasks. Whether recognized or not, for the nursing workers, how hard is a hard fact. In fact, a very present, especially if we considered the dual employment and weekly hours of work, mainly in the private sector, where it becomes excessive.

The result of the heavy work elements involved in the workload, this corresponds to the physical expenditure, and the static or dynamic set of skills that a person invests in the task. Do not forget that the distinction between physical, mental and psychic (affective or emotional) is purely theoretical.

The physical burden on the nursing workers differs from one service to another and is mainly due to the frequent operation of high energy cost. Lift, hold and transport sick or other charges, rebed, dressing, etc.. Sometimes using empirical techniques, assuming awkward postures, walk miles in search of material, are examples of uncomfortable situations.

Have different counters and work plans (beds, stands for infusions, sinks, toilets, faucets, etc..) tall not suited to measurements of the users and main- tain the standing posture almost always, it is undoubtedly of considerable physical load.

Another factor is the physical load and displacement distances, depending on the architecture and organization of work, in general, we walk a lot in hospitals. On average, 6.7 to $17.6 \mathrm{~km}$ per day, which is not small when compared with other professions that involve a lot of walking, such as waiter and postman. To cover these distances, you lose a significant amount of time that could be better applied for the benefit of the patient. However, the distances traveled, though long, alone does not account for things they must be related to the large amount of displacement (change of place), their motives and other factors of physical load.

To prevent bedsores, remake beds, checking vital signs, stand or lie the patient from the bed, the chair or the floor (after a fall), i.e., the very culture of nursing helps to absorb the harmful postures, being always foot, or worse still, leaning, crouching, pushing or pulling loads [10]. The nursing care involves activities ranging from those considered extremely simple to complex, requiring employees with different levels of knowledge and skills for its implementation. The occupational hazards are much higher for the professional nursing than for many other workers and overlook this fact may reduce the quality of services performed by this professional [9].

Karou Ishikawa who pioneered techniques of quality management in 60 years in Japan, invented the Ishikawa diagram, which is a basic tool in quality control. With a form of "fishbone" where the "head" of the fish is the main problem and the "bones" represent the potential causes of the problem, requiring investigation and resolution [8]. Thus, it is necessary to approach a macro ergonomics (physical, cognitive, psychosocial and organizational environment) to identify, minimize and eliminate all the risks inherent in the hospital environment.

As the literature supports a program of physical activity associated with a practical training on the mobilization and transfer of all patients and / or partially dependent, and ergonomic actions in the work process of nursing staff, can significantly reduce the number of days of absenteeism related to musculoskeletal disorders, to reduce discomfort (pain) and physical indicators such as improving flexibility and muscle strength of the chain back (lumbar region). 


\section{References}

[1] Alexandre, N. M. C., Moraes, M. A A ; Mahayri, N. Model of an orientation course on certain ergonomic and postural work of nursing personnel. Journal Brazilian of Occupational Health, n. 74, v. 19,1991 .

[2] Alexandre N.M.C., Moraes M.A.A., Filho H.R.C., Jorge A.S Assessment program to reduce back pain in nursing personnel. Journal Public Health 2001; 35 (4): 356-361.

[3] Alexandre N.M.C., Rogante M.M. Moving and transfer patients: postural and ergonomic aspects. Journal of the nursing school of the University São Paulo 2000; 34 (2):165-73.

[4] Benito, G. A. V.; Gontijo, L. A. The cognitive ergonomics: a benchmark analysis in the art of nursing care. Text nursing Context, Florianópolis, v. 05, n. 01, p. 92-110, 1996.

[5] Bulhões I., Risks of nursing work, Rio de Janeiro: Folha Carioca Editora, 1994.

[6] Gundewall B., Liljeqvist M., Hansson T. Primary prevention of back symptoms and absence from work. A prospective randomized study among hospital employees. Spine 1993;18:587-94.
••-Gurgueira G.P., Alexandre N.M.C., Filho H.R.C., Prevalence of musculoskeletal symptoms in nursing, Latin American journal of nursing 2003, 11, PP. 608-13.

[8] Ishikawa K., Loftus JH, (Eds): Introduction to quality control Tokyo, Japan: 3A Corporation; 1990.

•. Juibari L., Sanagu A., Farrokni N.: The relationship between knowledge of ergonomic science and the occupational health among nursing staff affiliated to Golestan University of Medical Sciences, Iran J Nurs Midwifery, 2010 15(4) 185-9

[10] Marziale, M. H. P.; Carvalho, E. C. Ergonomic conditions of work of the nursing staff in hospital cardiology unit. Latin American journal of nursing, Ribeirão Preto, v. 06, n. 01, p. 99-117, 1998.

[11] Marziale, M. H. P.; Robazzi, M. L. C. C. The posture adopted by the nursing staff in moving patients in bed and ergonomic adaptation of the technical procedure Acta paulista nursing, São Paulo, n. 03, p. 71-79, 2001

[12] Wisner, A. The intelligence at work: ergonomics in selected texts, São Paulo: Fundacentro, 1997. 